\title{
Expression Profiling in Pinus pinaster in Response to Infection with the Pine Wood Nematode Bursaphelenchus xylophilus
}

\author{
Daniel Gaspar ${ }^{1,2}$ (D), Cândida Trindade ${ }^{3}$, Ana Usié ${ }^{1,2}$, Brígida Meireles ${ }^{1,2}$ (D) , \\ Pedro Barbosa ${ }^{1,2}$ (1) , Ana M. Fortes ${ }^{4}$ (1) , Cátia Pesquita ${ }^{5}$, Rita L. Costa ${ }^{3, *}$ \\ and António M. Ramos ${ }^{1,2}$ \\ 1 Centro de Biotecnologia Agrícola e Agro-alimentar do Alentejo (CEBAL)/Instituto Politécnico \\ de Beja (IPBeja), Rua Pedro Soares, s.n.-Campus IPBeja/ESAB, Apartado 6158, 7801-908 Beja, Portugal; \\ daniel.gaspar@cebal.pt (D.G.); ana.usie@cebal.pt (A.U.); brigida.meireles@cebal.pt (B.M.); \\ pedro.barbosa@cebal.pt (P.B.); marcos.ramos@cebal.pt (A.M.R.) \\ 2 Instituto de Ciências Agrárias e Ambientais Mediterrânicas (ICAAM), Universidade de Évora, \\ Núcleo da Mitra, Apartado 94, 7006-554 Évora, Portugal \\ 3 Instituto Nacional de Investigação Agrária e Veterinária, I.P. (INIAV), Avenida da República, \\ Quinta do Marquês (edifício sede), 2780-157 Oeiras, Portugal; candida.smpp.trindade@gmail.com \\ 4 Faculdade de Ciências da Universidade de Lisboa (FCUL), BioSystems \& Integrative Sciences \\ Institute (BIOISI), Campo Grande, 1749-016 Lisboa, Portugal; margafortes@yahoo.com \\ 5 Faculdade de Ciências da Universidade de Lisboa (FCUL), LaSIGE, Campo Grande, \\ 1749-016 Lisboa, Portugal; cpesquita@di.fc.ul.pt \\ * Correspondence: rita.lcosta@iniav.pt; Tel.: +35-191-907-3379
}

Received: 22 June 2017; Accepted: 31 July 2017; Published: 3 August 2017

\begin{abstract}
Forests are essential resources on a global scale, not only for the ecological benefits, but also for economical and landscape purposes. However, in recent years, a large number of forest species have suffered a serious decline, with maritime pine being one of the most affected. In Portugal, the maritime pine forest has been devastated by the pine wood nematode (PWN), the causal agent of pine wilt disease. In this study, RNA-Seq data was used to characterize the maritime pine response to infection with PWN, by determining the differentially expressed genes and identifying the regulatory networks and pathways associated. The analyses showed clear differences between an early response that occurs immediately after inoculation and a late response that is observed seven days after inoculation. Moreover, differentially expressed genes related to secondary metabolism, oxidative stress and defense against pathogen infection were identified over different time points. These results provide new insights about the molecular mechanisms and metabolic pathways involved in the response of Pinus pinaster against PWN infection, which will be a useful resource in follow-up studies and for future breeding programs to select plants with lower susceptibility to this disease.
\end{abstract}

Keywords: RNA-sequencing; transcriptome analysis; gene expression; pine wilt disease; Pinus pinaster; Bursaphelenchus xylophilus

\section{Introduction}

Forests are much more than a large area of land covered with trees. They represent one of life's support systems on Earth, providing essential resources for a range of ecosystems. Furthermore, forests supply various products and services, generating a huge number of economic and social benefits. Due to the high commercial value of wood products, maritime pine (Pinus pinaster Ait.) is one of the main conifer species in southwestern Europe, covering approximately four million hectares in this region [1]. In Portugal, maritime pine is one of the predominant tree species, and by far the most 
widespread, mainly in the regions of Atlantic influence, covering more than 700 thousand hectares, which corresponds to $23 \%$ of the total forest surface [2].

In recent years there has been a worrying decline of a large number of forest species around the world, with maritime pine being one of the most affected [3]. This alarming decrease is caused by abiotic and biotic factors, of which the pine wood nematode (PWN), Bursaphelenchus xylophilus Steiner \& Buhrer, 1934 (Nickle, 1970) is one of the main biotic factors [4].

PWN is a quarantine organism in the European Union (Directive 77/93 EEC), being the causal agent of the pine wilt disease (PWD) that may kill a host tree within a short period of time after infection [5]. Mostly due to this pathogen, the total area occupied by P. pinaster suffered an abrupt decline in Portugal, with losses of 263,000 hectares between 1995 and 2010 [2]. As a result, P. pinaster went from being the main forest species, in terms of distribution and area, to the third, behind eucalyptus and cork oak. Recently, it was classified as an endangered species by the IUCN red list of threatened species [6].

PWN was reported for the first time in Portugal in 1999 [5], and in less than 10 years the whole P. pinaster area had been affected. PWN is transported between host trees by an insect vector, a longhorn cerambycid beetle (Monochamus galloprovincialis Oliv.) [7]. The transmission may occur in two forms: (i) by oviposition, where the female beetles lay their eggs under the bark of stressed or recently killed trees by the PWN, and the nematodes migrate to pupae just before adult beetles emerge, ensuring successful survival of the parasite. Note that due to the low frequency and efficiency in susceptible trees, such as P. pinaster, transmission by oviposition represents a secondary inoculation way [8]; (ii) by feeding, considered the most common pathway of transmission on susceptible trees, that occurs through beetle feeding wounds (primary transmission). Nematodes carried by beetles move into wounds and breed in the xylem, but the survival of nematodes is not guaranteed $[9,10]$. This is a close relationship between PWN and its vector beetle, resulting in the epidemiological cycle of PWD [11].

PWD expression depends not only on the pathogenicity of PWN and susceptibility of host trees but also on environmental conditions such as high temperature and large soil moisture, the optimal conditions for PWN proliferation [9]. The symptoms caused by PWD are common to other diseases, and therefore can easily be confused. A typical early symptom is needle discoloration. Needles turn grayish green, then tan, and finally brown. Then, resin flow ceases and the wood is dry when cut [4].

The defensive mechanisms of host trees can be divided into early and advanced stages [12]. In the first stage, defensive response occurs in both susceptible and resistant trees, while late response is found only in susceptible trees [12]. In the same species, it has been verified the existence of trees with different levels of susceptibility, some of which survive the infection, thus, constituting an opportunity for selective breeding. This has been the approach in breeding programs developed in China and Japan in the early sixties [13].

Transcriptome analysis based on next-generation sequencing data provides information about all transcriptional activity in a cell or organism. It is now the most commonly used approach, and has been applied to disease pathogenesis studies and identification of biomarkers [14]. For non-model organisms like $P$. pinaster, for which there is no reference genome sequence available, RNA-Seq is an efficient means to generate functional genomic data [15].

In order to understand the pathogenic mechanisms and reduce the damage caused by the PWD in Portuguese forests and respective ecosystems, several studies were performed [16-19] However, to our knowledge, the analysis of maritime pine molecular response based on RNA-Seq data was reported in only one approach [20]. In this study, was pointed out a set of candidate genes potentially involved in the response to PWN, mainly related with terpenoid metabolism, defense against pathogen attack and oxidative stress.

This work is an approach to PWD, using RNA-Seq data to characterize the maritime pine transcriptomic profile in the response to infection with Bursaphelenchus xylophilus, over three different time points after inoculation, by determining the differentially expressed (DE) genes, regulatory 
networks and pathways, with the purpose of identifying potential candidate genes that may later on be used in the selection of $P$. pinaster trees displaying resistance against PWD.

\section{Materials and Methods}

\subsection{Biological Material, Pine Wood Nematode Inoculation and Sampling}

A total of fourteen potted three-year-old Pinus pinaster trees were used in this study. These plants were derived from seeds and maintained in natural environmental conditions during the assay. Bursaphelenchus xylophilus culture was grown in PDA (Potato Dextrose Medium) with Botrytis cinerea. After a significant growth, a suspension of nematodes was transferred to test tubes with $5 \mathrm{~mL}$ of water and barley grains previously autoclaved. Later they were incubated for a week at $25{ }^{\circ} \mathrm{C}$ and relative humidity of $70 \%$, which represent optimal conditions for nematodes growth. Before inoculation, nematodes were extracted from test tubes using the Baermann funnel technique [21]. Then, the culture was placed at $4{ }^{\circ} \mathrm{C}$ to stop multiplication and passing from juvenile stage to adult stage.

Inoculation with PWN was conducted following the method of Futai and Furuno [22]. Shortly, a suspension with 2000 nematodes was pipetted into a small vertical wound $(1 \mathrm{~cm})$ made on the upper part of the main pine stem with a sterile scalpel. A sterilized piece of gauze was placed around the wound site and fixed with parafilm to maintain the optimal humidity level. This procedure was done in twelve P. pinaster plants, while the two remaining plants were used as control (inoculation with water).

Four sampling time points were established, including 6 h, 24 h, 48 h and 7 days after inoculation. For each time point, a set of three P. pinaster plants was collected. Briefly, a small piece of stem tree above inoculation point was cut and flash frozen at $-80^{\circ} \mathrm{C}$ for further RNA extraction.

\subsection{RNA Extraction, cDNA Synthesis, Library Preparation and Sequencing}

All collected samples were ground in liquid nitrogen and a total RNA extraction was performed from $2 \mathrm{~g}$ of plant material, according to an optimized method from Provost and colleagues [23]. Then, a DNase treatment was carried out following the instructions of the manufacturer (Kit TURBO DNA-free by Life Technologies, Hong Kong, China).

Approximately 1 microgram of total RNA was used for cDNA synthesis, following the ImProm-IITM Reverse Transcription System protocol kit (Promega, Madison, WI, USA). Before sequencing, four pools of cDNA were constructed (pool 1-control; pool 2-6 + 24 h; pool 3-48 h; pool 4-7 days).

cDNA libraries were constructed with the Ion Total RNA-Seq Kit v2 (Life Technologies, Hong Kong, China). Briefly, mRNA was fragmented with RNAse III. After short fragment removal, RNA adapters were ligated and the cDNA first and second strands synthesized. cDNA was then amplified with specific barcoded primers by PCR amplification and the resulting fragments selected for the correct size with magnetic beads.

Finally, the positive spheres from the four libraries were loaded into an Ion PI chip v2 and the transcriptomes were sequenced as single-end reads in the Ion Proton System (Thermo Fisher Scientific, Waltham, MA, USA) at Biocant (Cantanhede, Portugal). All procedures were carried out according to manufacturer's instructions.

\subsection{Pre-Processing RNA-Sequencing Data and Transcriptome Assembly}

The quality of the RNA-Seq reads from the four sequenced libraries was checked using FastQC software Version 0.11.5 [24], a quality control tool for high throughput sequence data. Based on the FastQC results, the thresholds for minimum average read quality and read length were established as 12 and $80 \mathrm{bp}$, respectively. These parameters were used to run Sickle tool Version 1.33 [25], which trimmed poor quality bases and adapters sequences from the raw reads, and produced a set of processed reads that were then used in the downstream analyses. 
Since no reference genome sequence is available for P. pinaster, it was necessary to perform a de novo transcriptome assembly. The processed reads from all libraries were assembled into contigs using Trinity 2.1.1 [26]. The contigs generated with the Trinity assembly were used as input for a run with CAP3 [27]. The resulting assembly was the basis for the next procedures, being used as the reference transcriptome assembly.

\subsection{Prediction of Candidate Coding Regions}

The sequences from the reference transcriptome were analyzed with TransDecoder-2.0.1 [28] to identify the open reading frames (ORF). The ORF transcripts identified were further scanned for homology to known proteins against the Swiss-Prot [29] and Pfam [30] databases by running BlastP [31] and HmmScan [32], respectively. In the end, TransDecoder provided the final set of candidate coding regions, namely the predicted genes representing the basis for their annotation.

\subsection{Mapping and Differential Expression Analysis}

Mapping the reads against the transcriptome assembly was performed using RapMap [33]. Before performing a differential gene expression analysis, it is common to determine the number of unique mapped reads, which was accomplished with SAMtools-1.3 [34]. Only the reads that mapped to a unique location in the reference transcriptome were used for downstream analyses.

The EdgeR package [35] of Bioconductor was used to identify transcripts that were differentially expressed between the conditions. To adjust for library sizes and skewed expression of transcripts, the estimated abundance values were normalized using the Trimmed Mean of M-values normalization method [36] included in the EdgeR package. As our experiment did not have replicates, it was necessary to determine the biological variability. Thus, in accordance with the EdgeR guidelines, a BCV (biological coefficient variation) of 0.1 was assigned [37]. This procedure has been successfully used previously in other studies, for which biological replicates were also not available [38]. After the identification of the differentially expressed (DE) genes, correction for multiple testing was performed by applying the Benjamini-Hochberg method [39] on the $p$-values, to control the false discovery rate (FDR). The final list of differentially expressed genes was generated after employing a threshold of 0.01 for the FDR.

\section{6. $q P C R$ Validation}

To perform the validation of the data from RNA-Seq, five DE genes were selected (water deficit inducible (Wdip), WRKY transcription factor 1 (WRKY), PR10 protein (Pr10), MYB-like transcriptional factor (Myb), TIR/NBS/LRR disease resistance protein (LRR) and primers designed using Primer3 software [40]. cDNA synthesis was performed using the ImProm-II TM Reverse Transcription System Kit (Promega) with $1 \mu \mathrm{g}$ of total RNA following manufacturer instructions. Relative expression quantification was performed with Rotor-Gene Q software 1.7 (Qiagen, Venlo, The Netherlands) using the SsoFast ${ }^{\mathrm{TM}}$ Eva Green SuperMix 1x (SYBR based system, Bio-Rad, Hercules, CA, USA); $250 \mathrm{nM}$ of each primer and $1 \mu \mathrm{L}$ of cDNA in a final volume of $20 \mu \mathrm{L}$. All samples were run in triplicate, and a no template control (NTC) and a housekeeping gene were used for every primer pair. PCR cycling conditions were $95^{\circ} \mathrm{C}$ for $3 \mathrm{~min}$, followed by 40 cycles at $95^{\circ} \mathrm{C} 10 \mathrm{~s}, 60^{\circ} \mathrm{C} 60 \mathrm{~s}$ and $72{ }^{\circ} \mathrm{C} 30 \mathrm{~s}$. A melting curve was generated for each reaction to assure specificity of the primers and the presence of primer-dimer. Primers efficiencies were assessed using a serial dilution of cDNA stock. The Elongation factor- 1 alpha was used as housekeeping gene and for normalization of expression of each gene.

To compare the RNA-Seq and qPCR results, a Pearson correlation was calculated using the Log2 of the normalized expression values.

\subsection{Transcriptome Annotation}

The ORFs transcripts identified by TransDecoder were used for transcriptome annotation. This procedure was performed using InterProScan [41,42]. The protein domains, gene ontology (GO) terms [43] and Kyoto Encyclopedia of Genes and Genomes (KEGG) pathways [44] associated with 
the genes annotated that are encoding enzymes were identified. A custom python script was run to filter GOs and KEGGs from the InterProScan output. Categorizer [45] was used for the analysis of the GOs. The list of GO IDs belonging to one of the GO categories, which includes Biological process (BP), Cellular component (CC) and Molecular function (MF), was used and classified by its corresponding subcategories against the GO Slim plant database [45]. The number of GOs was counted within each subcategory, and its percentage over the total set of GO IDs provided was reported.

Regarding the functional annotation for differential expressed genes, the contigs were annotated against the non-redundant National Center for Biotechnology Information (NCBI) plants database (version of August 2015) using BlastP (e-value $\left.1 \times 10^{-5}\right)$.

\subsection{Biological Networks Analysis}

In this study, Cytoscape [46] was used for visualization of molecular interaction networks. This type of analysis provided a deep knowledge about resistance mechanisms at the molecular level. Cytoscape analysis procedures began by establishing interactions between DE genes associated with KEGG pathways and GO terms. From the large amount of plugins and features available in Cytoscape to perform different types of studies, BiNGO [47] was selected to identify which GOs were statistically overrepresented in the sets of DE genes. Moreover, the Enrichment Map plugin [48] was also used with the results from BiNGO to visualize enrichment of specific functions. The statistical analysis was carried out with customized default values recommended by user's guidelines.

\subsection{SNP Calling}

Variant calling was performed with the GATK toolkit [49], which offers a variety of tools for variant discovery. Similarly to the differential expression analysis, only the unique mapped reads were used for SNP calling. A first set of variants was identified using the UnifiedGenotyper tool available in the GATK toolkit. This initial set of variants was then filtered, using the SelectVariants option with the parameters SNP quality (QUAL $\geq 60$ ), individual coverage (DP $\geq 15$ ) and genotype quality (GQ-phred quality $\geq 40$ ), in order to produce the final set of high-confidence SNPs. Finally, SnpEff was used to annotate and predict the effects of the filtered SNPs.

\subsection{Data Archiving Statement}

The raw sequences used in this work were submitted to the Sequence Read Archive (SRA) with the BioProject accession number PRJNA378402 and accession name "Pinus pinaster Transcriptome sequencing".

\section{Results}

\subsection{Pre-Processing of RNA-Sequencing Data and Transcriptome Assembly}

A total of 176,282,168 raw reads were generated for all libraries. After quality control using FastQC, low-quality bases were trimmed by Sickle and 144,422,207 high quality reads were obtained, with an average range length between $119 \mathrm{bp}$ and $122 \mathrm{bp}$ (Table 1). A total of $81.9 \%$ of the original number of reads were retained after applying the quality control procedures.

Table 1. Pre-processing statistics for each library.

\begin{tabular}{ccccc}
\hline Sample & $\begin{array}{c}\text { Number of } \\
\text { Sequenced Reads }\end{array}$ & $\begin{array}{c}\text { Average Read } \\
\text { Length (bp) }\end{array}$ & $\begin{array}{c}\text { Number of Reads } \\
\text { after QC }\end{array}$ & $\begin{array}{c}\text { \% Reads after } \\
\text { QC }\end{array}$ \\
\hline Pp01-Control $(0 \mathrm{~h})$ & $47,903,109$ & 122 & $39,091,399$ & 81.6 \\
Pp02-6h+24 h & $38,483,969$ & 119 & $30,863,177$ & 80.2 \\
Pp03-48 h & $44,943,925$ & 122 & $37,186,370$ & 82.7 \\
Pp04-7 days & $44,951,165$ & 121 & $37,281,261$ & 82.9 \\
Total & $176,282,168$ & 121 & $144,422,207$ & 81.9 \\
\hline
\end{tabular}


The de novo assembly performed with Trinity produced 483,428 contigs. The additional clustering of these contigs performed with CAP3 resulted in an improved assembly comprising 355,287 contigs with a total length of $147,022,102$ base pairs.

Regarding ORF prediction for the transcriptome assembly, 83,468 genes were predicted from the 355,287 assembled contigs.

\subsection{Mapping and Differential Expression Analysis}

The results regarding the mapped reads (MR) for each library are presented in Table 2. A total of 103,269,178 pre-processed reads were mapped by RapMap against the transcriptome assembly for all libraries, which corresponded to an average of $71.6 \%$ of the total number of pre-processed reads. The lowest percentage of MR (70.8\%) was obtained for the control library (Pp01). On the other hand, for the Pp02 library, which corresponds to the $6 \mathrm{~h}+24 \mathrm{~h}$ sampling time points after inoculation, the highest percentage of MR (73.3\%) was obtained (Table 2).

Table 2. Number of mapped reads, unique mapped reads and their percentages for each library.

\begin{tabular}{ccccc}
\hline Sample & $\begin{array}{c}\text { Number of Reads } \\
\text { Mapped }\end{array}$ & $\begin{array}{c}\text { Number of Unique } \\
\text { Mapped Reads }\end{array}$ & $\begin{array}{c}\text { \% of Mapped } \\
\text { Reads }\end{array}$ & $\begin{array}{c}\text { \% of Unique } \\
\text { Mapped Reads }\end{array}$ \\
\hline Pp01-Control & $27,683,922$ & $14,432,190$ & 70.8 & 36.9 \\
Pp02-6 h + 24h & $22,608,382$ & $12,162,427$ & 73.3 & 39.4 \\
Pp03-48 h & $26,553,659$ & $14,077,794$ & 71.4 & 37.9 \\
Pp04-7 days & $26,423,215$ & $13,828,813$ & 70.9 & 37.1 \\
Total & $103,269,178$ & $54,501,224$ & 71.6 & 37.7 \\
\hline
\end{tabular}

For all downstream analyses it was essential to filter the unique mapped reads (UMR) from this set of MR. A total of 54,501,224 UMR were retained, which corresponded to approximately $37.7 \%$ of total processed reads (Table 2). Similarly to MR, the lower percentage of UMR was detected in Pp01 (36.9\%), while the Pp02 library had the highest percentage (39.4\%) (Table 2).

Statistical analysis with EdgeR identified a total of 17,533 DE genes (adjusted $p$-value $\leq 0.01$ and FDR value $=0.01$ ) within the 42,594 significant tests. The number of significant tests (up and down regulated) for each comparison between two different stages is summarized in Figure S1. The highest number of significant tests was identified between the control sample (Pp01) and Pp02, where 4968 genes were up regulated and 5103 genes were down regulated. This result highlights the importance of studying early responses to pathogen attack. Moreover, 85 genes were always differentially expressed (up or down) in all comparisons.

Figure 1 shows the number of genes differentially expressed (up and down) uniquely for each comparison. These results were in agreement with the total number of significant tests, since the highest number of DE genes was present between Pp01 and Pp02.

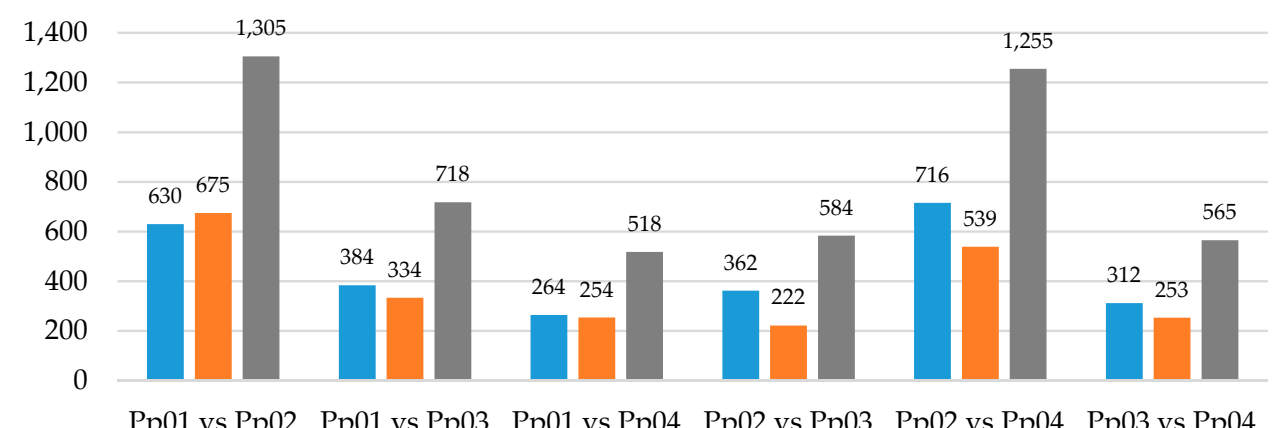

Figure 1. Number of differentially expressed genes (up and down) uniquely for each comparison. Tests up-regulated are shown in blue, tests down regulated are shown in orange and the total number of tests is shown in gray. 


\section{3. $q P C R$ Validation}

In order to validate the results from RNA-Seq data, five DE genes were selected to assess their expression by qPCR. The qPCR assay for the selected transcripts shows an expression pattern similar to the one obtained by RNA-Seq data analysis. Differential expression detected by RT-PCR was consistent with the RNA-Seq expression profiling of each of the selected transcripts. A correlation between the Log2 of the expression values of both RNA-Seq and qPCR data was performed and showed a positive correlation between the values obtained by these two different approaches (Figure 2 and Figure S2), which supports the accuracy of the RNA-Seq analyses.

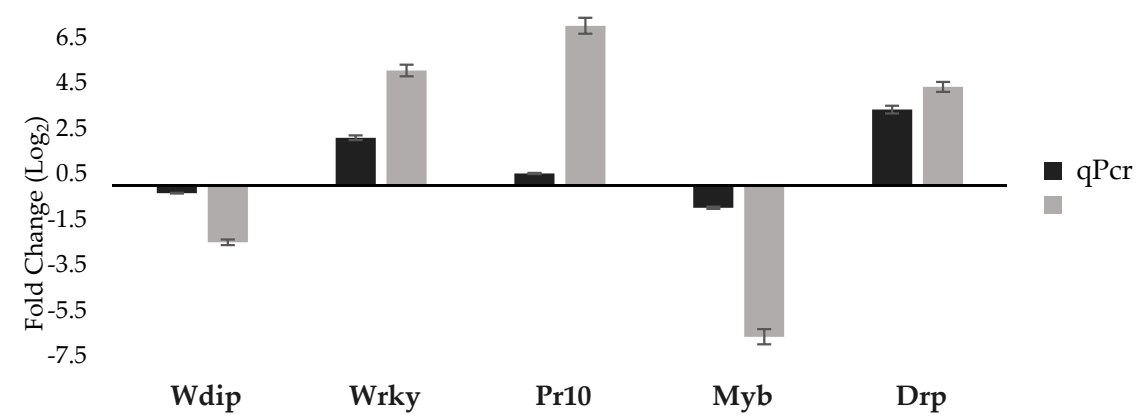

Figure 2. Fold Change for each of the transcripts selected for validation. The values are represented as the Log2 of the normalized expression value of both RNA-Seq and qPCR data, at time point Pp04.

\subsection{Transcriptome Annotation}

Functional annotation over the 83,468 predicted genes by TransDecoder was performed using BlastP against the NCBI NR-plants database, with results showing a total of 70,646 (84.6\%) annotated genes. However, $30.6 \%(25,545)$ of annotated genes had "Unknown" description, predominantly being associated to Picea sitchensis, a conifer of the Pinaceae family. From this set of annotated genes, the subset containing only the DE genes also contained 8996 with an "Unknown" description or no description available. Likewise for the DE genes, most of the "Unknown" descriptions were related to Picea sitchensis. A list of selected DE genes for analysis is showed in Table 3.

Table 3. Summary of selected DE genes (Up and Down) between different comparisons.

\begin{tabular}{|c|c|c|c|}
\hline Gene Annotation & Condition & Comparison & Log Fold-Change \\
\hline GDSL esterase/lipase & Up & Control vs. Pp02 & 12.4 \\
\hline Translationally-controlled tumor protein homolog & Up & Control vs. Pp02 & 11.8 \\
\hline Jacalin-related lectin 3 protein & Up & Control vs. Pp02 & 6.9 \\
\hline Cytokinin dehydrogenase 6-like & $\mathrm{Up}$ & Control vs. Pp02 & 6.9 \\
\hline Endoglucanase & Up & Control vs. Pp02 & 9.4 \\
\hline Acyl-CoA oxidase & Up & Control vs. Pp02 & 4.4 \\
\hline Thaumatin-like protein & $\mathrm{Up}$ & Control vs. Pp02 & 4.3 \\
\hline Nucleotide-binding site leucine-rich repeat (NBS-LRR) & Down & Control vs. Pp02 & -3.1 \\
\hline 12-oxophytodienoate reductase 3-like & Up & Control vs. Pp02 & 2.9 \\
\hline Iron superoxide dismutase & Up & Control vs. Pp02 & 1.9 \\
\hline Auxin-induced cell wall protein & Up & Control vs. Pp02 & 7.7 \\
\hline Multifunctional protein (MFP) & Up & Control vs. Pp02 & 1.3 \\
\hline Mildew resistance locus 6 calmodulin binding protein & Up & Control vs. Pp02 & 2.7 \\
\hline Sucrose synthase & Up & Control vs. Pp02 & 2.5 \\
\hline TMV resistance protein $\mathrm{N}$-like & Down & Control vs. Pp02 & -7.1 \\
\hline Phenylalanine ammonia-lyase & Up & Control vs. Pp02 & 2.1 \\
\hline Peroxidase & Up & Control vs. Pp02 & 7.7 \\
\hline GDSL esterase/lipase & Up & Control vs. Pp03 & 9.9 \\
\hline Translationally-controlled tumor protein homolog & Up & Control vs. Pp03 & 10.4 \\
\hline Endoglucanase & Up & Control vs. Pp03 & 9.7 \\
\hline Thaumatin-like protein & Up & Control vs. Pp03 & 2.5 \\
\hline (E)-4-hydroxy-3-methylbut-2-enyl diphosphate synthase & Up & Control vs. Pp03 & 4.3 \\
\hline Nucleotide-binding site leucine-rich repeat (NBS-LRR) & Down & Control vs. Pp03 & -12.5 \\
\hline GDSL esterase/lipase & Up & Control vs. Pp04 & 8.1 \\
\hline
\end{tabular}


Table 3. Cont.

\begin{tabular}{cccc}
\hline Gene Annotation & Condition & Comparison & Log Fold-Change \\
\hline Translationally-controlled tumor protein homolog & $\mathrm{Up}$ & Control vs. Pp04 & 9.6 \\
Jacalin-related lectin 3 protein & $\mathrm{Up}$ & Control vs. Pp04 & 8.6 \\
Cytokinin dehydrogenase 6-like & $\mathrm{Up}$ & Control vs. Pp04 & 6.9 \\
Endoglucanase & $\mathrm{Up}$ & Control vs. Pp04 & 9.1 \\
Acyl-CoA oxidase & $\mathrm{Up}$ & Control vs. Pp04 & 4.9 \\
Thaumatin-like protein & $\mathrm{Up}$ & Control vs. Pp04 & 3.1 \\
Pinosylvin synthase & $\mathrm{Up}$ & Control vs. Pp04 & 3.7 \\
(E)-4-hydroxy-3-methylbut-enyl diphosphate synthase & $\mathrm{Up}$ & Control vs. Pp04 & 2.8 \\
Nucleotide-binding site leucine-rich repeat (NBS-LRR) & Down & Control vs. Pp04 & -8.5 \\
Auxin-induced protein 1 & Down & Pp02 vs. Pp03 & -1.9 \\
Laccase & $\mathrm{Up}$ & Pp02 vs. Pp03 & 6.7 \\
Dehydrin & Down & Pp02 vs. Pp04 & -11.0 \\
Pathogenesis related 10 & Down & Pp02 vs. Pp04 & -3.0 \\
Pinosylvin synthase & $\mathrm{Up}$ & Pp02 vs. Pp04 & 2.6 \\
Heat shock protein & $\mathrm{Up}$ & Pp02 vs. Pp04 & 7.6 \\
Light harvesting complex protein & $\mathrm{Up}$ & Pp02 vs. Pp04 & 7.9 \\
Phospholipase D alpha 1-like & $\mathrm{Up}$ & Pp02 vs. Pp04 & 8.8 \\
Tau class glutathione S-transferase & $\mathrm{Up}$ & Pp03 vs. Pp04 & 2.7 \\
Pinosylvin synthase & $\mathrm{Up}$ & Pp03 vs. Pp04 & 3.6 \\
Nucleotide-binding site leucine-rich repeat (NBS-LRR) & $\mathrm{Up}$ & Pp03 vs. Pp04 & 3.5 \\
\hline
\end{tabular}

The protein domains were also identified for the set of predicted genes using InterProScan, providing information about the functional classes of GO terms and KEGG pathways. Over the set of predicted genes, $77.7 \%(64,853)$ had at least one protein domain identified, $46.4 \%(38,762)$ were associated with at least one GO term (BP: $29.6 \%$, CC: $11.3 \%$ and MF: $41.4 \%$ ) and 5.9\% (4904) were associated with at least one KEGG pathway. The total number of different GO terms and KEGG pathways identified over the whole gene set was 1810 and 111, respectively. Focusing just over the set of 17,553 DE genes, 9119 (52.0\%) were associated with at least one GO term and a total of 1292 different GO terms were found. Moreover, 1154 DE genes were associated with at least one KEGG pathway and a total of 102 different KEGG pathways were found. The most representative pathways for predicted genes and for DE genes, in terms of enzymes associated, are shown in Table 4.

Table 4. Summary of KEGG pathways ranked by the number of associated enzymes, detected in predicted genes and in DE genes.

\begin{tabular}{ccc}
\hline Pathways & Enzymes in All Set of Genes & Enzymes in DE Genes \\
\hline Purine metabolism & 37 & 24 \\
Pyrimidine metabolism & 26 & 18 \\
Aminoacyl-tRNA biosynthesis & 21 & 15 \\
Cysteine and methionine metabolism & 20 & 16 \\
Starch and sucrose metabolism & 19 & 16 \\
Porphyrin and chlorophyll metabolism & 20 & 12 \\
Phenylalanine, tyrosine and tryptophan biosynthesis & 18 & 14 \\
Pyruvate metabolism & 17 & 14 \\
Glycolysis/Gluconeogenesis & 17 & 15 \\
Carbon fixation in photosynthetic organisms & 13 & 12 \\
Terpenoid backbone biosynthesis & 17 & 7 \\
\hline
\end{tabular}

Additionally, CateGOrizer was used for further analysis of the GO terms, for both the whole set of predicted genes and the set of DE genes, identifying subcategories of each of the three GO categories (BP, MF and CC), against the GOSlim plant database.

With respect to the biological process branch, a total of 30 subcategories of GO terms were found. The most significant were cellular process (GO: 0009987) (32.8\%), metabolic process (GO: 0008152) $(26.9 \%)$ and biosynthetic process (GO: 0009058) (11.1\%) (Figure S3). In the case of cellular component, 26 subcategories of GO terms were identified. The largest proportion GOs were assigned to cell (GO: 0005623) (28.8\%), intracellular (GO: 0005622) (27\%) and cytoplasm (GO: 0005737) (11.4\%) (Figure S4). In the molecular function category, a total of 24 subcategories of GO terms were detected. 
In this category, the most representative terms were catalytic activity (GO: 0003824) (44.2\%), transferase activity (GO: 0016740) (13.8\%) and hydrolase activity (GO: 0016787) (11.7\%) (Figure S5).

Subsequently, to further investigate the biological response associated to PWN infection, a GOs analysis for DE genes among all conditions was performed. In this analysis, a total of $9119 \mathrm{DE}$ genes $(52.0 \%)$ associated with at least one GO term were identified and a total of 1292 different GO terms were found. For the biological process term 36 GO subcategories were identified, with a total of 1477 hits. The most representative subcategories were cellular process (GO: 0009987) (27.4\%), metabolic process (GO: 0008152) (22.6\%) and biosynthetic process (GO: 0009058) (9.1\%) (Figure S3). Regarding cellular component terms, 24 subcategories were found with a total of 486 hits. The subcategories with more hits were cell (GO: 0005623) (28.6\%), intracellular (GO: 0005622) (27.4\%) and cytoplasm (GO: 0005737) (12.4\%) (Figure S4). Lastly, for the molecular function term 24 subcategories were identified, with a total of 1039 hits. The most relevant subcategories were catalytic activity (GO: 0003824) (42.9\%), transferase activity (GO: 0016740) (12.9\%) and hydrolase activity (GO: 0016787) (11.6\%) (Figure S5).

\subsection{Biological Networks Analysis}

Understanding the molecular mechanisms involved in pine response to PWN infection depends on clarifying the biological activity of proteins. In this sense, a molecular interaction network analysis was performed using Cytoscape. Within the total of 102 KEGG pathways significantly regulated over the DE genes, phenylpropanoid biosynthesis, terpenoid backbone biosynthesis and flavonoid biosynthesis were prioritized for further discussion, because of the important role they play in the mechanisms of defense against PWN infection.

A total of 72 DE genes were associated with the phenylpropanoid biosynthesis pathway (Figure 3). This pathway, involved in the synthesis of secondary metabolites, plays a crucial role in the signaling mechanism, being a key mediator of the higher plants resistance towards pests [50]. The first reaction in the pathway is catalyzed by phenylalanine ammonia-lyase (PAL) (EC: 4.3.1.24). PAL links phenylpropanoid biosynthesis with the phenylalanine metabolism and can be induced by wounding or under other stress conditions. Its synthesis has been strongly associated to defense responses [51]. One of the main end products of this pathway is lignin. This polymer is determinant for the trees stability and robustness, acting mainly as physical barrier to pathogens [52]. Regulation of lignin components production is controlled by peroxidase (EC: 1.11.1.7). Both, PAL and peroxidase enzymes are found over-expressed in all the stages after inoculation with PWN.

For the pathways indicated, several proteins without functional annotation were named as unknown. Nevertheless, a metabolic network can still be associated to these proteins, by similarity, contextual methods (for example, homology-based function predictions) or both. In our work, the unknown proteins that are presented in the metabolic pathways were annotated in the UniProt database, which provides the link to the pathway information generated with Cytoscape (Table S1).

Terpenoid backbone biosynthesis pathway (Figure 4) has been associated to defensive mechanisms against biotic and abiotic stresses, which may act as insect repellents in a chemical response. This main pathway can be subdivided in two biosynthetic pathways, the mevalonate and the non-mevalonate (MEP/DOXP) pathway. A total of $31 \mathrm{DE}$ genes were associated to terpenoid backbone biosynthesis. Most of them codified two enzymes: hydroxymethylglutaryl-CoA reductase (HMGR) (EC: 1.1.1.34) and 1-deoxy-D-xylulose-5-phosphate (DXP) synthase (EC: 2.2.1.7). HMGR is involved in the synthesis of mevalonate, being an important control point in the mevalonate pathway [53]. HMGR induction is especially high in the first stages after PWN inoculation. Regarding 1-deoxy-D-xylulose-5-phosphate synthase, this enzyme is the first of the MEP/DOXP pathway, being considered important in the regulation of plastidial isoprenoid production [54]. 


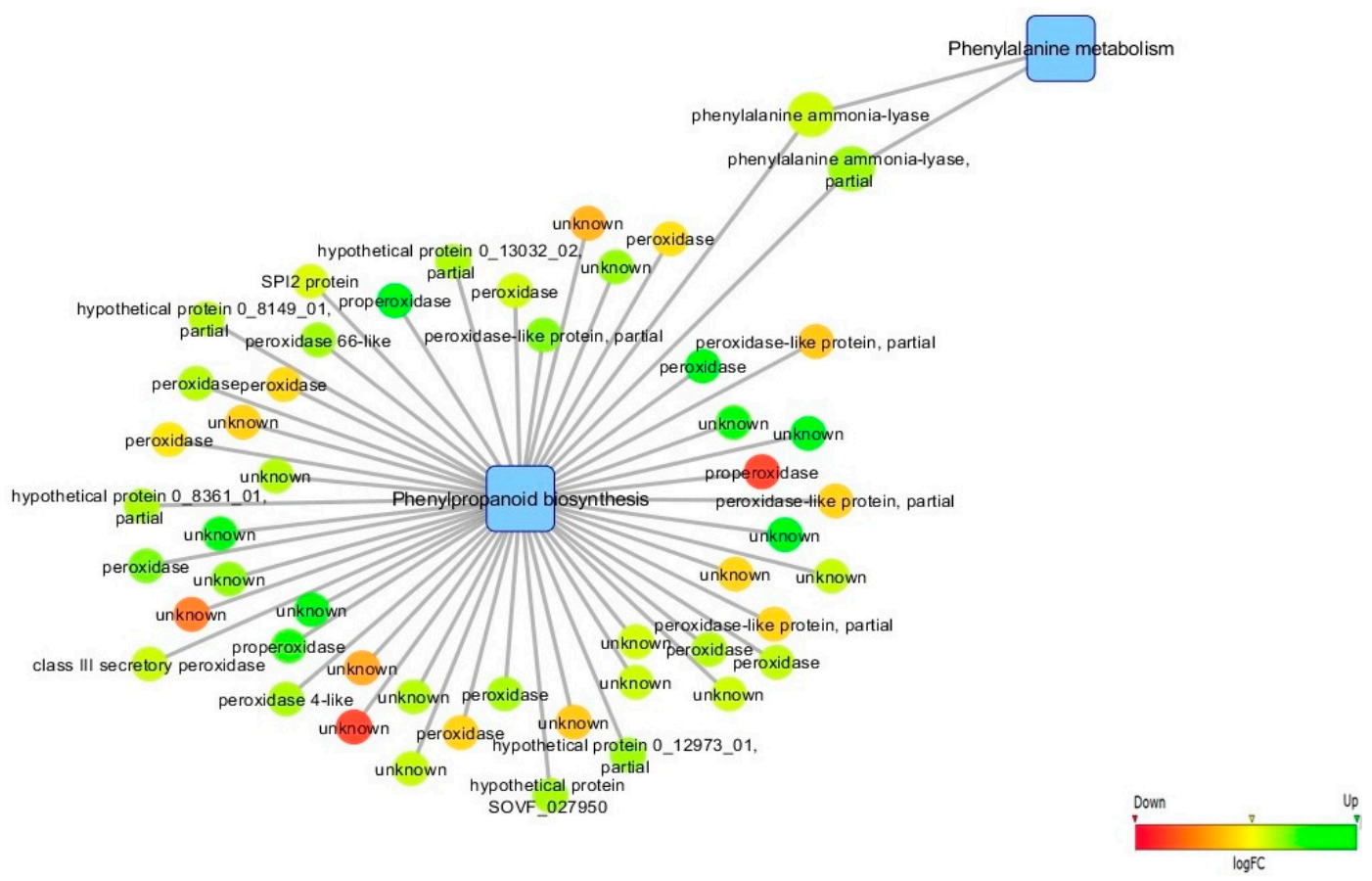

Figure 3. Phenylpropanoid biosynthesis pathway with interactions related to DE genes in the comparison Pp01-Pp02. The blue square nodes represent the pathways. The rest of the nodes represent all DE genes associated to the pathways. Note that due to the complexity of representing the expression values of those genes, the RGB color scale goes from the most down regulated in red to the most up regulated in green.

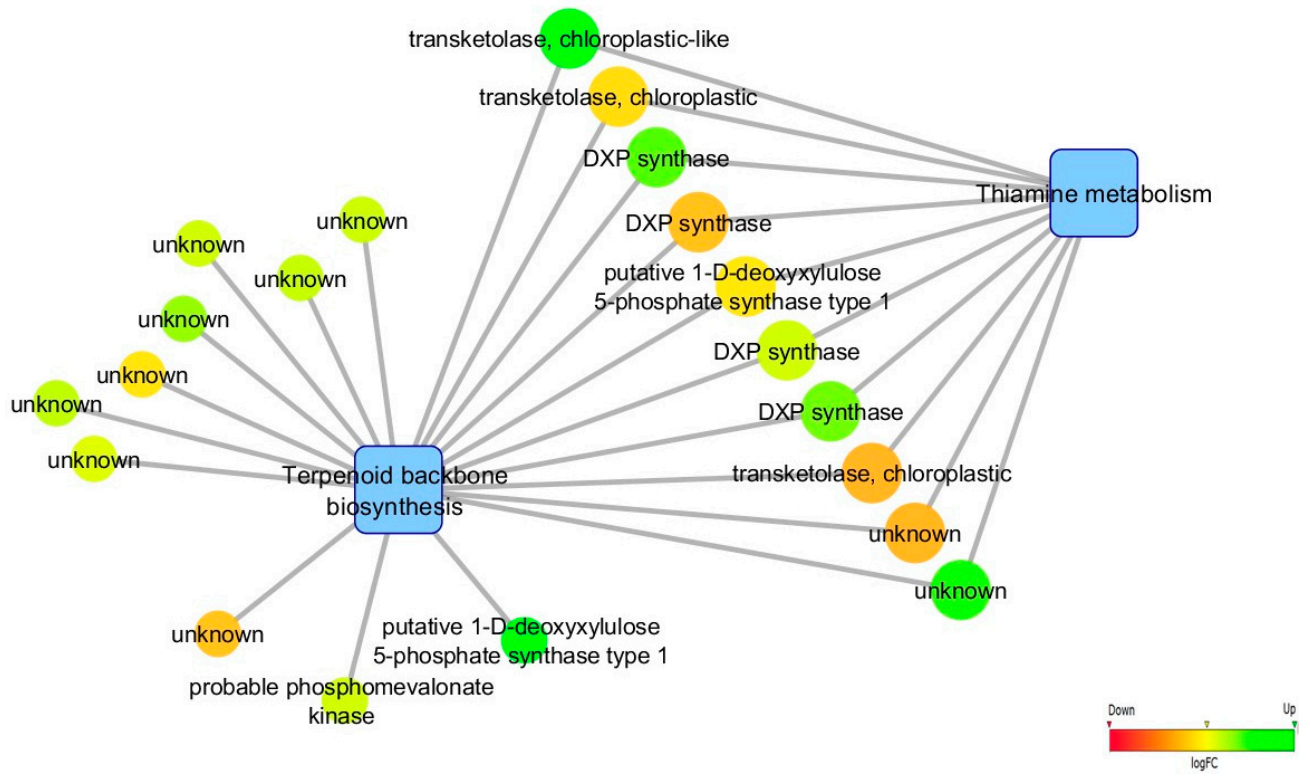

Figure 4. Terpenoid backbone biosynthesis pathway with interactions related to DE genes in the comparison Pp01-Pp02. The blue square nodes represent the pathways. The rest of the nodes represent all DE genes associated to the pathways. Note that due to the complexity of representing the expression values of those genes, the RGB color scale goes from the most down regulated in red to the most up regulated in green.

In the flavonoid biosynthesis pathway a total of $9 \mathrm{DE}$ genes were identified (Figure 5), all being highly expressed in early stages after PWN inoculation. Flavonoids are one of the largest classes 
of phenolics, a group of secondary metabolites produced by plants to defend themselves against pathogens. A key enzyme in this pathway is chalcone synthase (EC: 2.3.1.74), which is induced in plants under stress conditions. This enzyme plays a decisive role in the synthesis of a large set of flavonoid metabolites, being involved in the salicylic acid defense pathway [55]. Another important enzyme is chalcone isomerase (EC: 5.5.1.6), which catalyzes the cyclization of a chalcone into a flavone [56]. While chalcone synthase is highly induced in the first stage after PWN inoculation, chalcone isomerase is highly induced in the late stages after inoculation, both causing the accumulation of flavonoid and isoflavonoid phytoalexins in plant tissues.

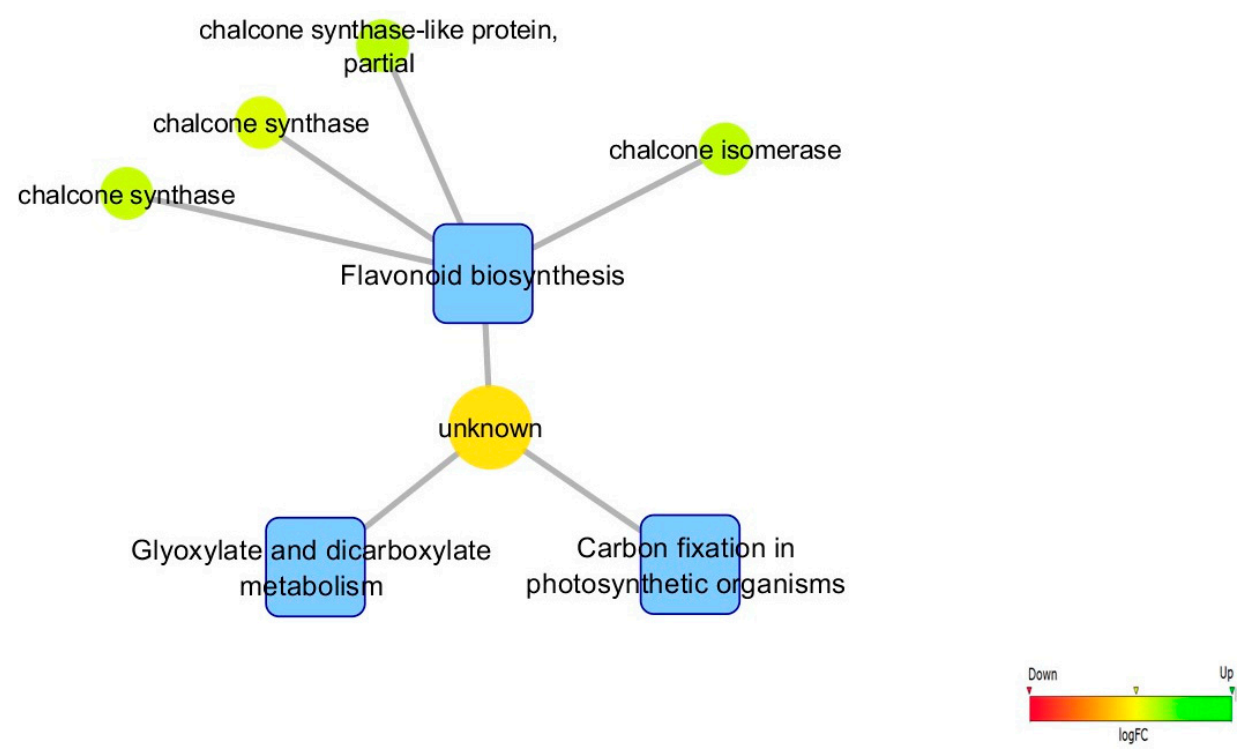

Figure 5. Flavonoid biosynthesis pathway with interactions related to DE genes in the comparison: Pp01-Pp02. The blue square nodes represent the pathways. The rest of the nodes represent all DE genes associated to the pathways. Note that due to the complexity of representing the expression values of those genes, the RGB color scale goes from the most down regulated in red to the most up regulated in green.

Regarding the GO networks, the analysis was focused in subcategories related to signaling system and to plant survival mechanisms under stress conditions. Thus, with respect to signal transduction (GO: 0007165), which mediates the sensing and processing of stimuli, 120 interactions over DE genes were detected, identifying a high level of some capital metabolites in all stages after inoculation. Molecular switches in plant signal, such as Rab7/RabG-famlily small GTPase and a small tab-related GTPase were induced immediately after PWN inoculation and remain highly induced over time. This suggests that these two proteins may act as a trigger in the maritime pine defensive response against PWN infection. A study in other plant species [57] reported that GTPases family is induced by external signals and plays a crucial role in the regulation of multiple responses in plants against pathogens.

A total of $116 \mathrm{DE}$ genes were associated with response to oxidative stress (GO: 0006979). This high number of associated genes makes sense, since oxidative stress is one of the typical symptoms caused by PWN infection. Within this term, glutathione peroxidase $1(\mathrm{Gpx})$ was identified as highly induced in all the stages after inoculation. Gpx is an enzyme whose main biological role is to protect the organism from oxidative damage, acting as antioxidant, by the inactivation of hydrogen and lipids peroxides [58].

Concerning response to stress (GO: 0006950), a total of $75 \mathrm{DE}$ genes related with this term were identified. Over this term, dehydrin1 is hugely expressed in all stages after inoculation. Dehydrins are involved in plant response and adaptation to abiotic and biotic stress [59]. Moreover, abscisic 
acid stress ripening protein 1-like is also over-expressed after inoculation; however, its biological role in stress conditions remains understudied.

The results of the over-expression analysis for the gene ontology terms, performed by BiNGO, related with the DE genes identified between the control sample and the first stage after inoculation, are presented in Figures S6 and S7. In total, two cellular components and three molecular functions were over represented in the control sample. Regarding the biological process, there was no statistical evidence of overrepresentation (Figure S6). On the other hand, five biological processes, four cellular components and one molecular function were over represented in the first stage after inoculation (Figure S7).

\subsection{SNP Calling Analysis}

For SNP discovery and filtering, GATK was used with stringent parameters. Variants were called using the UnifiedGenotyper and further filtering was performed using the SelectVariants option. In total, 36,295 different SNPs were detected. Among these SNPs, 31.9\% were found in exons, while $30.6 \%$ were detected in an intergenic region, a portion of a contig without gene prediction (Table 5). Moreover, with respect to the SNPs found in each functional class, $48.5 \%$ were associated to missense mutations, $50.7 \%$ to silent mutations and less than $1 \%$ to nonsense mutations (Table 6 ).

Table 5. SNP calling analysis. Number and percentage of effects by region.

\begin{tabular}{ccc}
\hline Region & Count & Percentage \\
\hline Exon & 15,232 & $31.9 \%$ \\
Intergenic & 14,600 & $30.6 \%$ \\
Splice site region & 1 & $<0.1 \%$ \\
Transcript & 31 & $0.1 \%$ \\
UTR 3 Prime & 9072 & $19.0 \%$ \\
UTR 5 Prime & 8718 & $18.3 \%$ \\
\hline
\end{tabular}

Table 6. SNP calling analysis. Number and percentage of effects by functional class.

\begin{tabular}{ccc}
\hline Type & Count & Percentage \\
\hline MISSENSE & 7410 & $48.5 \%$ \\
NONSENSE & 121 & $0.8 \%$ \\
SILENT & 7732 & $50.7 \%$ \\
\hline
\end{tabular}

\section{Discussion}

In this study, an RNA-Seq based approach was used to determine the transcriptomic profile of maritime pine in different stages after inoculation with PWN, to identify candidate genes associated with the response mechanisms to the infection.

One of the main challenges in RNA-Seq studies for non-model organisms like maritime pine is to produce de novo transcriptome assembly. This is a crucial step, which can yield some erroneous assembled contigs, due to the nature of high-throughput sequencing reads, which can contain sequencing errors, and the algorithms used for de novo assembly, which can also generate assembly artifacts, i.e., contigs that do not represent true regions of the transcriptome. These factors may have had an impact in this study since the rate of predicted genes from the set of assembled contigs was low (83,468 genes were predicted from 355,287 assembled contigs). Even though genomic information for several conifer species has been generated, and compiled in the TreeGenes database [60], the number of genomic resources for maritime pine remains limited, which is another relevant factor that may have contributed to the low rate of predicted genes. When a reference genome is not available, the genetic description contained in the assembled transcripts can only be successfully identified by homology if the protein products have homologies in different protein databases, giving a set of predicted genes. 
Hence, in the case this type of analysis is applied in species that yield a distinct set of expressed genes, with little or no homology when compared with all gene sequences deposited in the databases commonly used in these studies, it is possible to end up with a significant percentage of contigs for which no gene could be predicted. From the total genes predicted in this study, 70,646 (84.6\%) of them were annotated, providing a genomic resource to further deepen the study of genes involved in the transcriptomic response of pine wood to infection with PWN. However, 25,545 annotated genes had "Unknown" description, mainly associated to Picea sitchensis, which reinforces the need to strengthen the genomic resources for maritime pine, ideally with the availability of a fully sequenced and annotated reference genome.

The comparison of sequence data from all libraries revealed a total of 17,533 DE genes, a number that was obtained using a FDR value of 0.01 , which is a more stringent correction for multiple testing when compared with the traditionally used FDR value of 0.05 . Despite the stringency applied in the statistical methodologies used to generate the final list of differentially expressed genes, the unavailability of replicates may be responsible for increasing the number of false-positive results. Functional annotation with GO terms for predicted genes resulted in 38,762 (46.4\%) unigenes with at least one assignment into one of the three categories of GO terms (BP, MF and CC). In each of the GO categories, the GO terms fell mainly into two or three subcategories. The GO subcategories identified with more evidences are in accordance with other reports [20], and may represent a typical gene expression profile for P. pinaster after infection with PWN.

Most plant defensive responses to pathogens have evolved into a complex system, simultaneously combining several mechanisms and pathways. To identify possible pathways involved in defense against PWN, a KEGG analysis for our set of predicted genes was performed. The different KEGG pathways associated with the predicted genes are in agreement with the Physiome Project Models [61] for P. pinaster. The most prevalent pathways were purine and pyrimidine metabolism. These subunits of nucleic acids are major energy carriers and precursors for the synthesis of nucleotide cofactors such and NAD and SAM [62].

In this study, the identification of several DE genes related to biotic and abiotic stresses, hormonal regulation and cell wall defense further validates the hypothesis that these mechanisms play a crucial role in the plant defense system involved in the response to PWD.

\subsection{Infection Leads to de novo Transcription of Genes Involved in Biotic Stress Response, Phenylpropanoid/Terpenoid Metabolisms and Hormonal Regulation}

The genes induced only after inoculation with PWN are important to understand the mechanisms activated when the plant is infected by this pathogen. Indeed, a set of genes over-expressed in all conditions after inoculation (Pp02-6 h $+24 \mathrm{~h}, \mathrm{Pp} 03-48 \mathrm{~h}$ and Pp04-7 days) were identified, including the GDSL esterase/lipase that is potentially involved in defensive reactions [63,64], and a translationally-controlled tumor protein homolog, which participates in important cellular processes like the protection of cells against various stresses and apoptosis [65]. Moreover, the pattern of over-expression after inoculation was also detected for the gene that codifies a jacalin-related lectin 3 protein (JRL), which is often associated with biotic and abiotic stimuli. JRLs proteins have been referenced as a component of the plant defense system, although their role is not well understood yet, due to their structural diversity [66]. In general, the results obtained in the present study are in agreement with the set of candidate genes, related with the response to PWN infection, reported in different studies $[20,67]$. For instance, the relevance of terpenoid metabolism in maritime pine defense against PWN, important in the resin production process, was pinpointed by Santos and colleagues [20]. In that study, the (E)-4-hydroxy-3-methylbut-2-enyl diphosphate (HMB-PP) reductase gene was found highly expressed after inoculation, an expression pattern that was also identified in Pp03 and Pp04 for HMB-PP synthase. Likewise, the thaumatin-like protein (TLP) was found to be deeply involved in plant defense system as a response to biotic and abiotic stress. Various studies imply its importance in plant resistance $[68,69]$, even though its role remains unclear. For example, towards 
a pathogen attack and under stress, these proteins confer tolerance and induce stress resistance [68]. In our work the gene codifying this protein is highly induced immediately after inoculation, decreasing its expression levels slightly over time. The difference observed for the expression pattern of this gene, relative to the study carried by $\mathrm{Xu}$ and colleagues [67] in Pinus massoniana, may indicate a specific response for maritime pine.

Genes involved in hormonal regulation, such as cytokinin dehydrogenase 6-like and auxin-induced cell wall protein, were identified as highly expressed after infection with PWN. In our study, the expression of cytokinins supports the possibility that they are involved in signaling defense responses after a pathogen attack, improving the resistance to pathogens [70].

Phytohormones are responsible for various important physiological processes, from plant growth to plant defense [71]. The response to an insect attack is mediated by plant hormones, as primary signal in the regulation of plant defense. The salicylic acid (SA), hormone ethylene (ET), jasmonic acid (JA) and its derivates are the major defense hormones. Differentially expressed genes codifying important enzymes in jasmonate biosynthesis, such as 12-oxophytodienoate reductase 3-like (OPR3), which is fundamental in this biosynthesis, acyl-CoA oxidase and a multifunctional protein (MFP) found to be associated with wound-induced, were identified through the different comparisons. Genes codifying transcription factors involved in the hormone signaling at local and distant tissues were also identified differentially expressed after inoculation. Most of the genes identified have higher levels of expression in the last stages post inoculation. A faster recognition of the pathogen is important for an efficient response, since the timing of the hormonal production can determine if the plant becomes more resistant to the nematode.

As already mentioned, the highest number of DE genes was identified between the control sample (Pp01) and Pp02, which clearly indicates an immediate response to PWN after inoculation. This observation is in accordance with previous results obtained in Pinus thunbergii Parl., that suggested an early response to PWN in susceptible and in resistant trees [72]. Within this early stage of response, and when compared with the control sample, several genes potentially involved in the defensive response were detected, evidencing the activation of the defense mechanisms in the infected plant. These genes included the mildew resistance locus 6 calmodulin binding protein gene, which triggers a defensive response in the occurrence of an infection caused by a foreign body [73]. The processes used by the PWN to invade the Pinus pinaster tissues are likely to represent a very similar mechanism that is used by the powdery mildew, hence these results provide further support for the involvement of the mildew resistance locus 6 calmodulin binding protein gene in the initial response of plants to infections. The sucrose synthase gene also displayed over-expression in the Pp02 time point. This gene codes for an enzyme that provides metabolites for the synthesis of cellulose and callose, and plays an important role in secondary cell wall synthesis [74,75]. Genes codifying TMV resistance protein N-like and nucleotide-binding site leucine-rich repeat (NBS-LRR) disease resistance proteins were identified in the control sample. The high expression of these proteins, which are relevant in the plant immune response, suggests that the plant recognizes and triggers the defense system [76]. Comparing the control with all stages after inoculation, the NBS-LRR proteins showed a lower expression in the inoculation stages. These proteins are involved in the pathogen recognition and should act at an early stage for an effective response. In our work, these proteins only increased their values of expression in the last stage of inoculation, which may be too late for the plants to recover and combat the nematode.

Cytoscape analysis showed relevant interactions between the DE genes and KEGG pathways. Some enzymes appear to be directly associated with plants defense, being an important connection between relevant pathways, such as terpenoid backbone biosynthesis and thiamine metabolism, against biotic and abiotic stresses. In our work, the phenylpropanoid biosynthesis can be a relevant pathway, not only due to its connection with the phenylalanine metabolism by PAL, but also for the high number of peroxidase genes over-expressed in the Pp02. The higher expression of PAL genes, responsible for the first step in this pathway, can be a response to the wounds caused by the vector. 


\subsection{Infection Leads to a Reprogramming of Cell Wall Metabolism Putatively Involved in Cell Wall Reinforcement}

The over-expression of peroxidase genes during PWD may be related with the oxidation of phenolic residues, likely the substrates of lignin and suberin, into cell wall polymers in the infected tissues [51].

Enzymes involved in cell wall modifications were found differentially expressed, endoglucanase being the most highly expressed in the second and third time points. The endoglucanase is responsible for the catalysis of cellodextrin in cellobiose, the smallest subunit of cellulose, being also related with cell wall modifications in infected plants [77]. Thus, the over-expression of this enzyme as a response to infection, suggests that not just proteins related to defensive mechanisms are used to fight the infection, since some mechanisms are activated to reconstruct the cell damage originated by the PWN.

Additionally, when comparing the Pp02 with Pp03 a gene encoding a laccase was found highly expressed in the Pp03. These kinds of proteins are involved in lignin biosynthesis and plant pathogenesis [78]. Lignin forms important structural materials in the support tissues of vascular plants. Hence, it makes sense that one of the mechanisms activated is to reinforce the cell walls, especially in wood and bark.

\subsection{Late Responses to Infection Seem to Be Involved in the Mitigation of Stress Caused by an Inefficient Early Response}

A previous study reported a late response to infection with PWN in susceptible trees [72]. This late response is observed in our study, and may occur approximately one week after inoculation, due to the large amount of DE genes that were identified between Pp02 and Pp04. Measuring differences between early and late responses can elucidate the different mechanisms activated. When comparing the two stages, the higher expression of the dehydrin gene in Pp02 is relevant since it has been associated to plant response and adaptation to abiotic stress such as water stress, being involved in a mechanism commonly developed in these stages [59]. Thus, considering that the PWD results in destruction of parenchyma cells surrounding xylem resin ducts, causing a dysfunction of the water-conducting system, the involvement of this gene to prevent water loss makes sense. The pathogenesis related type 10 gene was also highly expressed at this stage. This gene was already found in conifers, displaying a transient accumulation in needles of drought-stressed trees [79]. As a consequence of the water stress, the needles become drought stressed, which is one of the most characteristic symptoms of PWD. Stress proteins, such as heat shock, were encoded by over-expressed genes in Pp04. Under stressful conditions they protect cells by stabilizing unfolded proteins, giving the cell time to repair damaged proteins. Heat shock proteins are highly conserved among different organisms [63]. Although it is unclear its precise role in Pinus pinaster, it seems that this protein is involved in the plant's effort to combat the PWN. The gene coding the light harvesting complex protein was highly expressed in Pp04. It is involved in light energy transfer to one chlorophyll-a molecule at the reaction center of a photosystem. Although this protein is not directly related with the defensive mechanism, it plays an important role trying to maximize the production of energy, which could be essential in helping the cellular systems triggered within the response. Genes encoding NBS-LRR proteins were identified highly expressed in this time point. NBS-LRR proteins are capable of recognizing a wide variety of pathogens and initiate a hypersensitive response (HR), resulting in cell death. The NBS-LRR proteins are divided in two major groups, involved in downstream specificity and signaling regulation [80], both of them showing high levels of expression in the Pp04. The behavior of NBS-LRR proteins through the different time point comparisons pointed out one more difference between the early and the late phase of response and a possible reason why the early response is not effective.

When comparing the Pp02 and Pp03 time points, the auxin-induced protein 1 was found over-expressed in Pp02. Auxins regulate and control vital mechanisms, being involved in growth, 
development and in defense via signaling, involving different interactions of molecules [81]. This protein seems to have an important role in the first stage of the response against the infection.

Lastly, regarding the comparison between Pp03 and Pp04, a phospholipase D alpha 1-like and a tau class glutathione S-transferase were over-expressed in Pp04. The former plays an important role in various cellular processes, including response to stress [82], while the latter has been associated to the oxidative stress response mechanism [83].

Recent studies related to PWD reported a set of genes associated to response to PWN infection. Several biotic-stress resistance genes were identified after PWN inoculation by Shin and colleagues in Japanese red pine [72], including the pinosylvin synthase and iron superoxide dismutase genes. The pinosylvin synthase was found over-expressed only in Pp04, while the iron superoxide dismutase genes were over expressed immediately after inoculation. Pinosylvin, which belongs to stilbenoids family, has been associated to phytoalexin induction, mainly in young pine trees exposed to biotic stress [84]. Moreover, pinosylvin is a key metabolite that can kill nematodes [85]. The presence of pinosylvin observed only in the late response against PWD, is an important feature that must be further analyzed, namely in tolerant and resistant Pinus species to PWN, since it can be one of the reasons why the first response to the infection is inefficient. The iron superoxide dismutase gene plays an important role in cell protection against oxidative stress [86].

The response displayed by maritime pine against PWN infection is clearly very complex and dynamic, however, in the end it still fails to prevent plant death as a result of the infection. This study provides an explanation for the possible reasons why the response of maritime pine to PWN infection is so inefficient. The comparison with the response of a tolerant Pinus species, for the same time points after infection (study under progress) will help unveiling what are the preponderant genes and pathways associated with resistance to PWD.

The SNP calling analysis performed in this study yielded a total of 36,295 SNPs, of which $69.2 \%$ were identified in exons and $30.6 \%$ were located in intergenic regions. The analysis of the SNP effects by functional class, performed only for the 15,263 SNPs located in exons and transcripts, revealed that over than $50 \%$ had a silent effect, which means that the SNP does not change the protein sequence. However, about $48.5 \%$ displayed a missense effect. In these situations, these changes are responsible for coding a different amino acid. When a new amino acid is coded, the sequence of the protein coded by a particular gene is also changed. These changes may occur between amino acids with markedly different properties, which in turn can affect the enzyme catalytic activity, or affect the secondary and tertiary structure of the protein, among others. Additionally, from a total of 4061 SNPs identified within the 17,533 DE genes, 15 were found in the sequences of genes discussed in more detail in the present work. There were 11 SNPs displaying a missense effect in the exon regions of the genes that codify the GDSL esterase/lipase, auxin induced cell wall and dehydrin proteins. Moreover, the two genes codifying the phenylalanine ammonia-lyase and auxin induced cell wall proteins respectively present a SNP in their 3' UTR region. This type of variation might affect transcription and translation and could be responsible for differences in gene expression. The two remaining SNPs were identified in the genes that encode the pathogenesis related 10 and jacalin-related lectin 3 proteins, generating a new stop codon, known as nonsense SNP. This type of SNP is responsible for the change of a coding codon to a stop codon, resulting in the inactivation of the respective gene [87]. Hence, these are very important SNPs whose effect on potential resistance to PWD can be tested in larger pine tree populations where resistance phenotypic data might be available for genome wide association studies (GWAS).

\section{Conclusions}

Currently, PWD, caused by Bursaphelenchus xylophilus, is the most deadly maritime pine disease. This study establishes a new approach for the understanding of the molecular response of maritime pine, which is susceptible to PWN, over different time points after inoculation with PWN. Clear insights related with the defense mechanisms of Pinus pinaster against PWN were identified. The functional annotation of the predicted genes revealed the complexity of the system involved in the response 
against PWN, combining a number of mechanisms and pathways, simultaneously. As pointed out in previous studies, the occurrence of two phases of response against PWN was identified from the results of the differential expression analysis: an early response that occurs immediately after infection, and a late response that is developed approximately seven days after infection. Future studies will focus the analysis on the comparisons between for P. pinaster and a tolerant Pinus species, for the same time points, in order to try to understand which response is more effective to prevent the pathogen progression after infection. Moreover, the high number of DE genes found between the early and the late responses suggests that these two phases may have significant differences at the molecular level. The set of candidate genes identified over the different time points after inoculation will be a useful resource in future studies and breeding programs to select plants with lower susceptibility to PWD. Moreover, the SNPs identified in this study will be available to be tested in larger populations with available phenotypic records for resistance to PWD, thereby enabling the possibility of identification of molecular markers linked with this very important economic and biological trait in maritime pine.

Supplementary Materials: The following are available online at www.mdpi.com/1999-4907/8/8/279/s1, Figure S1: Total number of significant tests (up and down) between each comparison. Tests up-regulated are shown in blue, tests down regulated are shown in orange and the total number of tests is shown in gray, Figure S2: Correlation between the results from RNA-Seq and qPCR for the transcripts selected to perform validation, at time point Pp04, Figure S3: Distribution of the most representative biological process subcategories. The results for predicted genes are shown in blue and for DE genes in orange, Figure S4: Distribution of the most representative cellular component subcategories. The results for predicted genes are shown in blue and for DE genes in orange, Figure S5: Distribution of the most representative molecular function subcategories. The results for predicted genes are shown in blue and for DE genes in orange, Figure S6: Overrepresentation of cellular component and molecular function terms in control, obtained by BINGO. Color bar in the right lower quadrant indicates level of significance from low (yellow) to high (orange). The size of the nodes is proportional to the number of genes in GO category. Statistical analysis was performed with a hypergeometrical test and a $p$-value of $<0.05$, Figure S7: Overrepresentation of biological processes, cellular component and molecular function terms in first stage (Pp01), obtained by BINGO. Color bar in the right lower quadrant indicates level of significance from low (yellow) to high (orange). The size of the nodes is proportional to the number of genes in GO category. Statistical analysis was performed with a hypergeometrical test and a $p$-value of $<0.05$, Table S1: List of proteins with "unknown" annotation associated to flavonoid biosynthesis, terpenoid backbone biosynthesis and phenylpropanoid biosynthesis pathways. GI: Gene Identifier; GB: Gene Bank identifier.

Acknowledgments: Authors acknowledge the funding provided by Project REPHRAME of 7th Framework programme: "Development of improved methods for detection, control and eradication of pine wood nematode in support of EU Plant Health policy". Financial support for D. Gaspar, A. Usié, B. Meireles, P. Barbosa and A.M. Ramos was provided by Investigador FCT project IF/00574/2012/CP1209/CT0001: "Genetic characterization of national animal and plant resources using next-generation sequencing". A.M. Fortes was funded by FCT Investigator FCT050 (IF/00169/2015) and PEst-OE/BIA/UI4046/2014.

Author Contributions: Rita L. Costa conceived and designed the study and supervised the laboratorial experiments; Cândida Trindade performed the laboratorial experiments; Daniel Gaspar performed bioinformatics analyses of the data; Ana Usié, Brígida Meireles and Pedro Barbosa contributed in the bioinformatics analyses; António M. Ramos coordinated the bioinformatics analyses; Rita L. Costa, Daniel Gaspar, Ana Usié, Brígida Meireles, Ana M. Fortes, Cátia Pesquita and António M. Ramos interpreted the results; Daniel Gaspar and António M. Ramos wrote the manuscript; Ana Usié, Ana M. Fortes, Cátia Pesquita and Rita L. Costa revised the manuscript; All authors have read and approved this version of the manuscript.

Conflicts of Interest: The authors declare no conflict of interest.

\section{References}

1. Plomion, C.; Pionneau, C.; Brach, J.; Costa, P.; Baillères, H. Compression wood-responsive proteins in developing xylem of maritime pine (Pinus pinaster Ait.). Plant Physiol. 2000, 123, 959-969. [CrossRef] [PubMed]

2. Uva, J.S. IFN6-Áreas dos usos do solo e das espécies florestais de Portugal continental. Inst. Conserv. Nat. Florestas I.P. 2013, 1, 1-35.

3. Mota, M.M.; Futai, K.; Vieira, P. Pine Wilt Disease And The Pinewood Nematode, Bursaphelenchus Xylophilus. In Integrated Management of Fruit Crops Nematodes; Springer: Dordrecht, The Netherlands, 2009; pp. 253-274. 
4. Futai, K.; Sutherland, J.R.; Takeuchi, Y. Pine Wilt Disease; Springer: Tokyo, Japan, 2008; ISBN 978-4-431-75655-2.

5. Mota, M.; Braasch, H.; Bravo, M.A.; Penas, A.C.; Burgermeister, W.; Metge, K.; Sousa, E. First report of Bursaphelenchus xylophilus in Portugal and in Europe. Nematology 1999, 1, 727-734. [CrossRef]

6. Farjon, A. A Handbook of the World's Conifers; Brill: Leiden, The Netherlands, 2010; ISBN 9789004177185.

7. Sousa, E.; Bravo, M.A.; Pires, J.; Naves, P.; Penas, A.C.; Bonifácio, L.M.M. Bursaphelenchus xylophilus (Nematoda: Aphelenchoididae) associated with Monochamus galloprovincialis (Coleoptera: Cerambycidae) in Portugal. Nematology 2001, 3, 89-91. [CrossRef]

8. Naves, P.M.; Camacho, S.; De Sousa, E.; Quartau, J.A. Transmission of the pine wood nematode Bursaphelenchus xylophilus through oviposition activity of Monochamus galloprovincialis (Coleoptera: Cerambycidae). Entomol. Fenn. 2007, 18, 193-198.

9. Fielding, N.J.; Evans, H.F. The pine wood nematode Bursaphelenchus xylophilus (Steiner and Buhrer) Nickle (= B. lignicolus Mamiya and Kiyohara): An assessment of the current position. Forestry 1996, 69, 35-46. [CrossRef]

10. Edwards, O.R.; Linit, M.J. Transmission of Bursaphelenchus xylophilus through Oviposition Wounds of Monochamm carolinensis (Coleoptera: Cerambycidae). J. Nematol. 1992, 24, 133-139. [PubMed]

11. Naves, P.M.; Camacho, S.; de Sousa, E.M.; Quartau, J.A. Transmission of the pine wood nematode Bursaphelenchus xylophilus through feeding activity of Monochamus galloprovincialis (Col., Cerambycidae). J. Appl. Entomol. 2007, 131, 21-25. [CrossRef]

12. Fukuda, K. Physiological process of the symptom development and resistance mechanism in pine wilt disease. J. For. Res. 1997, 2, 171-181. [CrossRef]

13. Jusheng, H. A brief account of forest tree improvment in China. Genet. Resour. Inf. 1985, 14, 2-6.

14. Wang, Z.; Gerstein, M.; Snyder, M. RNA-Seq: A revolutionary tool for transcriptomics. Nat. Rev. Genet. 2009, 10, 57-63. [CrossRef] [PubMed]

15. Parchman, T.L.; Geist, K.S.; Grahnen, J.A.; Benkman, C.W.; Buerkle, C.A. Transcriptome sequencing in an ecologically important tree species: Assembly, annotation, and marker discovery. BMC Genom. 2010, 11, 180. [CrossRef] [PubMed]

16. Mota, M.M.; Takemoto, S.; Takeuchi, Y.; Hara, N.; Futai, K. Comparative Studies between Portuguese and Japanese Isolates of the Pinewood Nematode, Bursaphelenchus xylophilus. J. Nematol. 2006, 38, 429-433. [PubMed]

17. Naves, P.M.; Sousa, E.; Rodrigues, J.M. Biology of Monochamus galloprovincialis (Coleoptera, Cerambycidae) in the Pine Wilt Disease Affected Zone, Southern Portugal. Silva Lusit. 2008, 16, 133-148.

18. Valadas, V.; Oliveira, S.; Espada, M.; Laranjo, M.; Mota, M.; Barbosa, P. The pine wood nematode, Bursaphelenchus xylophilus, in Portugal: Possible introductions and spread routes of a serious biological invasion revealed by molecular methods. Nematology 2012, 14, 899-911. [CrossRef]

19. Vicente, C.S.L.; Nascimento, F.; Espada, M.; Barbosa, P.; Mota, M.; Glick, B.R.; Oliveira, S. Characterization of Bacteria Associated with Pinewood Nematode Bursaphelenchus xylophilus. PLoS ONE 2012, 7, e46661. [CrossRef] [PubMed]

20. Santos, C.S.; Pinheiro, M.; Silva, A.I.; Egas, C.; Vasconcelos, M.W. Searching for resistance genes to Bursaphelenchus xylophilus using high throughput screening. BMC Genom. 2012, 13, 599. [CrossRef] [PubMed]

21. Baermann, G. Ein einfache Methode zur Auffindung von Anklyostomum (Nematoden) Larven in Erdproben. Ned. Tijdschr. Geneeskd. 1917, 57, 131-137.

22. Futai, K.; Furuno, T. The variety of resistances among pine species to pine wood nematode, Bursaphelenchus lignicolus. Bull. Kyoto Univ. For. 1979, 51, 23-36.

23. Le Provost, G.; Herrera, R.; Paiva, J.A.; Chaumeil, P.; Salin, F.; Plomion, C. A micromethod for high throughput RNA extraction in forest trees. Biol. Res. 2007, 40, 291-297. [CrossRef] [PubMed]

24. FastQC-A Quality Control Tool for High Throughput Sequence Data. Available online: http://www. bioinformatics.babraham.ac.uk/projects/fastqc (accessed on 20 September 2016).

25. Sickle: A Windowed Adaptive Trimming Tool for FASTQ Files Using Quality. Available online: https:/ / github. com/najoshi/sickle (accessed on 20 September 2016). 
26. Grabherr, M.G.; Haas, B.J.; Yassour, M.; Levin, J.Z.; Thompson, D.A.; Amit, I.; Adiconis, X.; Fan, L.; Raychowdhury, R.; Zeng, Q.; et al. Full-length transcriptome assembly from RNA-Seq data without a reference genome. Nat. Biotechnol. 2011, 29, 644-652. [CrossRef] [PubMed]

27. Huang, X.; Madan, A. CAP3: A DNA sequence assembly program. Genome Res. 1999, 9, 868-877. [CrossRef] [PubMed]

28. Haas, B. TransDecoder (Find Coding Regions Within Transcripts). Available online: http://transdecoder. github.io (accessed on 16 May 2016).

29. Boeckmann, B.; Bairoch, A.; Apweiler, R.; Blatter, M.-C.; Estreicher, A.; Gasteiger, E.; Martin, M.J.; Michoud, K.; O'Donovan, C.; Phan, I.; et al. The SWISS-PROT protein knowledgebase and its supplement TrEMBL in 2003. Nucleic Acids Res. 2003, 31, 365-370. [CrossRef] [PubMed]

30. Finn, R.D.; Coggill, P.; Eberhardt, R.Y.; Eddy, S.R.; Mistry, J.; Mitchell, A.L.; Potter, S.C.; Punta, M.; Qureshi, M.; Sangrador-Vegas, A.; et al. The Pfam protein families database: Towards a more sustainable future. Nucleic Acids Res. 2015, 44, D279-D285. [CrossRef] [PubMed]

31. Altschul, S.F.; Gish, W.; Miller, W.; Myers, E.W.; Lipman, D.J. Basic local alignment search tool. J. Mol. Biol. 1990, 215, 403-410. [CrossRef]

32. Eddy, S.R. Multiple alignment using hidden Markov models. Proc. Int. Conf. Intell. Syst. Mol. Biol. 1995, 3, 114-120. [PubMed]

33. Srivastava, A.; Sarkar, H.; Gupta, N.; Patro, R. RapMap: A Rapid, Sensitive and Accurate Tool for Mapping RNA-seq Reads to Transcriptomes. Bioinformatics 2016, 32, i192-i200. [CrossRef] [PubMed]

34. Li, H.; Handsaker, B.; Wysoker, A.; Fennell, T.; Ruan, J.; Homer, N.; Marth, G.; Abecasis, G.; Durbin, R. The Sequence Alignment/Map format and SAMtools. Bioinformatics 2009, 25, 2078-2079. [CrossRef] [PubMed]

35. Robinson, M.D.; McCarthy, D.J.; Smyth, G.K. edgeR: A Bioconductor package for differential expression analysis of digital gene expression data. Bioinformatics 2009, 26, 139-140. [CrossRef] [PubMed]

36. Robinson, M.D.; Oshlack, A. A scaling normalization method for differential expression analysis of RNA-seq data. Genome Biol. 2010, 11, R25. [CrossRef] [PubMed]

37. McCarthy, D.J.; Chen, Y.; Smyth, G.K. Differential expression analysis of multifactor RNA-Seq experiments with respect to biological variation. Nucleic Acids Res. 2012, 40, 4288-4297. [CrossRef] [PubMed]

38. Sebastiana, M.; Vieira, B.; Lino-Neto, T.; Monteiro, F.; Figueiredo, A.; Sousa, L.; Pais, M.S.; Tavares, R.; Paulo, O.S. Oak Root Response to Ectomycorrhizal Symbiosis Establishment: RNA-Seq Derived Transcript Identification and Expression Profiling. PLoS ONE 2014, 9, e98376. [CrossRef] [PubMed]

39. Yoav, B.; Yosef, H. Controlling the False Discovery Rate: A Practical and Powerful Approach to Multiple Testing. J. R. Stat. Soc. 1995, 57, 289-300.

40. Untergasser, A.; Nijveen, H.; Rao, X.; Bisseling, T.; Geurts, R.; Leunissen, J.A.M. Primer3Plus, an enhanced web interface to Primer3. Nucleic Acids Res. 2007, 35, W71-W74. [CrossRef] [PubMed]

41. Quevillon, E.; Silventoinen, V.; Pillai, S.; Harte, N.; Mulder, N.; Apweiler, R.; Lopez, R. InterProScan: Protein domains identifier. Nucleic Acids Res. 2005, 33, W116-W120. [CrossRef] [PubMed]

42. Jones, P.; Binns, D.; Chang, H.-Y.; Fraser, M.; Li, W.; McAnulla, C.; McWilliam, H.; Maslen, J.; Mitchell, A.; Nuka, G.; et al. InterProScan 5: Genome-scale protein function classification. Bioinformatics 2014, 30, 1236-1240. [CrossRef] [PubMed]

43. Ashburner, M.; Ball, C.A.; Blake, J.A.; Botstein, D.; Butler, H.; Cherry, J.M.; Davis, A.P.; Dolinski, K.; Dwight, S.S.; Eppig, J.T.; et al. Gene ontology: Tool for the unification of biology. The Gene Ontology Consortium. Nat. Genet. 2000, 25, 25-29. [CrossRef] [PubMed]

44. Kanehisa, M.; Goto, S. KEGG: kyoto encyclopedia of genes and genomes. Nucleic Acids Res. 2000, 28, 27-30. [CrossRef] [PubMed]

45. Zhi-Liang, H.; Jie, B.; James, M.R. CateGOrizer: A Web-Based Program to Batch Analyze Gene Ontology Classification Categories. Online J. Bioinform. 2008, 9, 108-112.

46. Shannon, P.; Markiel, A.; Ozier, O.; Baliga, N.S.; Wang, J.T.; Ramage, D.; Amin, N.; Schwikowski, B.; Ideker, T. Cytoscape: A software environment for integrated models of biomolecular interaction networks. Genome Res. 2003, 13, 2498-2504. [CrossRef] [PubMed]

47. Maere, S.; Heymans, K.; Kuiper, M. BiNGO: A Cytoscape plugin to assess overrepresentation of gene ontology categories in biological networks. Bioinformatics 2005, 21, 3448-3449. [CrossRef] [PubMed] 
48. Merico, D.; Isserlin, R.; Stueker, O.; Emili, A.; Bader, G.D. Enrichment map: A network-based method for gene-set enrichment visualization and interpretation. PLoS ONE 2010, 5, e13984. [CrossRef] [PubMed]

49. McKenna, A.; Hanna, M.; Banks, E.; Sivachenko, A.; Cibulskis, K.; Kernytsky, A.; Garimella, K.; Altshuler, D.; Gabriel, S.; Daly, M.; et al. The Genome Analysis Toolkit: A MapReduce framework for analyzing next-generation DNA sequencing data. Genome Res. 2010, 20, 1297-1303. [CrossRef] [PubMed]

50. Vogt, T. Phenylpropanoid Biosynthesis. Mol. Plant 2010, 3, 2-20. [CrossRef] [PubMed]

51. Gómez-Vásquez, R.; Day, R.; Buschmann, H.; Randles, S.; Beeching, J.R.; Cooper, R.M. Phenylpropanoids, phenylalanine ammonia lyase and peroxidases in elicitor-challenged cassava (Manihot esculenta) suspension cells and leaves. Ann. Bot. 2004, 94, 87-97. [CrossRef] [PubMed]

52. Sattler, S.E.; Funnell-Harris, D.L. Modifying lignin to improve bioenergy feedstocks: Strengthening the barrier against pathogens? Front. Plant Sci. 2013, 4, 70. [CrossRef] [PubMed]

53. Stermer, B.A.; Bianchini, G.M.; Korth, K.L. Regulation of HMG-CoA reductase activity in plants. J. Lipid Res. 1994, 35, 1133-1140. [PubMed]

54. Wright, L.P.; Phillips, M.A. Measuring the activity of 1-deoxy-D-xylulose 5-phosphate synthase, the first enzyme in the MEP pathway, in plant extracts. Methods Mol. Biol. 2014, 1153, 9-20. [CrossRef] [PubMed]

55. Dao, T.T.H.; Linthorst, H.J.M.; Verpoorte, R. Chalcone synthase and its functions in plant resistance. Phytochem. Rev. 2011, 10, 397-412. [CrossRef] [PubMed]

56. Gensheimer, M.; Mushegian, A. Chalcone isomerase family and fold: No longer unique to plants. Protein Sci. 2004, 13, 540-544. [CrossRef] [PubMed]

57. Liu, F.; Guo, J.; Bai, P.; Duan, Y.; Wang, X.; Cheng, Y.; Feng, H.; Huang, L.; Kang, Z. Wheat TaRab7 GTPase Is Part of the Signaling Pathway in Responses to Stripe Rust and Abiotic Stimuli. PLoS ONE 2012, 7, e37146. [CrossRef] [PubMed]

58. Navrot, N.; Collin, V.; Gualberto, J.; Gelhaye, E.; Hirasawa, M.; Rey, P.; Knaff, D.B.; Issakidis, E.; Jacquot, J.-P.; Rouhier, N. Plant Glutathione Peroxidases Are Functional Peroxiredoxins Distributed in Several Subcellular Compartments and Regulated during Biotic and Abiotic Stresses. Plant Physiol. 2006, 142, 1364-1379. [CrossRef] [PubMed]

59. Hanin, M.; Brini, F.; Ebel, C.; Toda, Y.; Takeda, S.; Masmoudi, K. Plant dehydrins and stress tolerance: Versatile proteins for complex mechanisms. Plant Signal. Behav. 2011, 6, 1503-1509. [CrossRef] [PubMed]

60. Wegrzyn, J.L.; Lee, J.M.; Tearse, B.R.; Neale, D.B. TreeGenes: A forest tree genome database. Int. J. Plant Genom. 2008, 412875. [CrossRef] [PubMed]

61. Bassingthwaighte, J.B. Strategies for the Physiome Project. Ann. Biomed. Eng. 2000, 28, 1043-1058. [CrossRef] [PubMed]

62. Moffatt, B.A.; Ashihara, H. Purine and pyrimidine nucleotide synthesis and metabolism. Arabidopsis Book 2002, 1, e0018. [CrossRef] [PubMed]

63. Ling, H. Sequence analysis of GDSL lipase gene family in Arabidopsis thaliana. Pak. J. Biol. Sci. 2008, 11, 763-767. [CrossRef]

64. Oh, S., II; Park, A.R.; Bae, M.S.; Kwon, S.J.; Kim, Y.S.; Lee, J.E.; Kang, N.Y.; Lee, S.; Cheong, H.; Park, O.K. Secretome Analysis Reveals an Arabidopsis Lipase Involved in Defense against Alternaria brassicicola. Plant Cell 2005, 17, 2832-2847. [CrossRef] [PubMed]

65. Bommer, U.A.; Thiele, B.J. The translationally controlled tumour protein (TCTP). Int. J. Biochem. Cell Biol. 2004, 36, 379-385. [CrossRef]

66. Xiang, Y.; Song, M.; Wei, Z.; Tong, J.; Zhang, L.; Xiao, L.; Ma, Z.; Wang, Y. A jacalin-related lectin-like gene in wheat is a component of the plant defence system. J. Exp. Bot. 2011, 62, 5471-5483. [CrossRef] [PubMed]

67. Xu, L.; Liu, Z.-Y.; Zhang, K.; Lu, Q.; Liang, J.; Zhang, X.-Y. Characterization of the Pinus massoniana transcriptional response to Bursaphelenchus xylophilus infection using suppression subtractive hybridization. Int. J. Mol. Sci. 2013, 14, 11356-11375. [CrossRef] [PubMed]

68. Cao, J.; Lv, Y.; Hou, Z.; Li, X.; Ding, L. Expansion and evolution of thaumatin-like protein (TLP) gene family in six plants. Plant Growth Regul. 2016, 79, 299-307. [CrossRef]

69. Liu, J.-J.; Sturrock, R.; Ekramoddoullah, A.K.M. The superfamily of thaumatin-like proteins: Its origin, evolution, and expression towards biological function. Plant Cell Rep. 2010, 29, 419-436. [CrossRef] [PubMed] 
70. Zalabák, D.; Pospíšilová, H.; Šmehilová, M.; Mrízová, K.; Frébort, I.; Galuszka, P. Genetic engineering of cytokinin metabolism: Prospective way to improve agricultural traits of crop plants. Biotechnol. Adv. 2013, 31, 97-117. [CrossRef] [PubMed]

71. Wani, S.H.; Kumar, V.; Shriram, V.; Sah, S.K. Phytohormones and their metabolic engineering for abiotic stress tolerance in crop plants. Crop J. 2016, 4, 162-176. [CrossRef]

72. Shin, H.; Lee, H.; Woo, K.S.; Noh, E.W.; Koo, Y.B.; Lee, K.J. Identification of genes upregulated by pinewood nematode inoculation in Japanese red pine. Tree Physiol. 2009, 29, 411-421. [CrossRef] [PubMed]

73. Bouché, N.; Yellin, A.; Snedden, W.A.; Fromm, H. Plant-specific calmodulin-binding proteins. Annu. Rev. Plant Biol. 2005, 56, 435-466. [CrossRef] [PubMed]

74. Nairn, C.J.; Lennon, D.M.; Wood-Jones, A.; Nairn, A.V.; Dean, J.F.D. Carbohydrate-related genes and cell wall biosynthesis in vascular tissues of loblolly pine (Pinus taeda). Tree Physiol. 2008, 28, 1099-1110. [CrossRef] [PubMed]

75. Parrotta, L.; Faleri, C.; Cresti, M.; Cai, G. Heat stress affects the cytoskeleton and the delivery of sucrose synthase in tobacco pollen tubes. Planta 2016, 243, 43-63. [CrossRef] [PubMed]

76. Belkhadir, Y.; Subramaniam, R.; Dangl, J.L. Plant disease resistance protein signaling: NBS-LRR proteins and their partners. Curr. Opin. Plant Biol. 2004, 7, 391-399. [CrossRef] [PubMed]

77. Doi, R.H.; Kosugi, A. Cellulosomes: Plant-cell-wall-degrading enzyme complexes. Nat. Rev. Microbiol. 2004, 2, 541-551. [CrossRef] [PubMed]

78. Christopher, L.P.; Yao, B.; Ji, Y. Lignin Biodegradation with Laccase-Mediator Systems. Front. Energy Res. 2014, 2, 12. [CrossRef]

79. Dubos, C. Drought differentially affects expression of a PR-10 protein, in needles of maritime pine (Pinus pinaster Ait.) seedlings. J. Exp. Bot. 2001, 52, 1143-1144. [CrossRef] [PubMed]

80. McHale, L.; Tan, X.; Koehl, P.; Michelmore, R.W. Plant NBS-LRR proteins: Adaptable guards. Genome Biol. 2006, 7, 212. [CrossRef] [PubMed]

81. Carna, M.; Repka, V.; Skupa, P.; Sturdik, E. Auxins in defense strategies. Biologia (Bratisl) 2014, 69, 1255-1263. [CrossRef]

82. Canonne, J.; Froidure-Nicolas, S.; Rivas, S. Phospholipases in action during plant defense signaling. Plant Signal. Behav. 2011, 6, 13-18. [CrossRef] [PubMed]

83. Kilili, K.G.; Atanassova, N.; Vardanyan, A.; Clatot, N.; Al-Sabarna, K.; Kanellopoulos, P.N.; Makris, A.M.; Kampranis, S.C. Differential roles of tau class glutathione S-transferases in oxidative stress. J. Biol. Chem. 2004, 279, 24540-24551. [CrossRef] [PubMed]

84. Preisig-müller, R.; Schwekendiek, A.; Brehm, I.; Reif, H.-J.; Kindl, H. Characterization of a pine multigene family containing elicitor-responsive stilbene synthase genes. Plant Mol. Biol. 1999, 39, 221-229. [CrossRef] [PubMed]

85. Kodan, A.; Kuroda, H.; Sakai, F. A stilbene synthase from Japanese red pine (Pinus densiflora): Implications for phytoalexin accumulation and down-regulation of flavonoid biosynthesis. Proc. Natl. Acad. Sci. USA 2002, 99, 3335-3339. [CrossRef] [PubMed]

86. Karlsson, M.; Stenlid, J.; Olson, Å. Identification of a superoxide dismutase gene from the conifer pathogen Heterobasidion annosum. Physiol. Mol. Plant Pathol. 2005, 66, 99-107. [CrossRef]

87. Cingolani, P.; Platts, A.; Wang, L.L.; Coon, M.; Nguyen, T.; Wang, L.; Land, S.J.; Lu, X.; Ruden, D.M. A program for annotating and predicting the effects of single nucleotide polymorphisms, SnpEff: SNPs in the genome of Drosophila melanogaster strain w1118; iso-2; iso-3. Fly (Austin) 2012, 6, 80-92. [CrossRef] [PubMed]

(C) 2017 by the authors. Licensee MDPI, Basel, Switzerland. This article is an open access article distributed under the terms and conditions of the Creative Commons Attribution (CC BY) license (http:/ / creativecommons.org/licenses/by/4.0/). 